\title{
THERMAL FATIGUE EFFECTS ON TENSILE PROPERTIES OF SURFACE-TREATED NATURAL FIBER/POLYLACTIC ACID GREEN COMPOSITE
}

\author{
HIDEAKI KATOGI ${ }^{1}$, KENICHI TAKEMURA $^{2}$ \& SHUNSUKE KAWASAKI ${ }^{2}$ \\ ${ }^{1}$ Department of Human Environmental Sciences, Jissen Women's University, Japan \\ ${ }^{2}$ Department of Mechanical Engineering, Kanagawa University, Japan
}

\begin{abstract}
This study investigated alkali treatment effects on tensile properties of plain woven jute-fiberreinforced green composites under thermal fatigue. Concentrations of the alkali treatment were $1 \%$ and $15 \%$. Thermal fatigue tests of non-treated and alkali-treated green composites and polylactic acid (PLA) were conducted at temperatures of $35-80^{\circ} \mathrm{C}$. The maximum number of cycles was $10^{3}$ cycles. Quasi-static tensile tests were conducted using non-treated and alkali-treated green composite and PLA samples after thermal fatigue. Surfaces of non-treated and alkali-treated jute fibers were observed. Results show the following. Tensile strength of non-treated green composite decreased along with an increased number of cycles. Tensile strengths of $1 \%$ and $15 \%$ alkali-treated green composites exhibited almost no change until $10^{2}$ cycles. Young's moduli of non-treated and $1 \%$ and $15 \%$ alkali-treated green composites exhibited almost no change until $10^{2}$ cycles. Tensile strengths of $1 \%$ and $15 \%$ alkali-treated green composites at $10^{3}$ cycles were lower than those of $1 \%$ and $15 \%$ alkali-treated green composites at $10^{2}$ cycles. Furthermore, Young's moduli of non-treated and $1 \%$ and $15 \%$ alkali-treated green composites at $10^{3}$ cycles were lower than those of non-treated, $1 \%$ and $15 \%$ alkali-treated green composites at $10^{2}$ cycles. Tensile properties of PLA remained almost unchanged under thermal fatigue. Surface observations revealed a smooth surface of non-treated jute fiber. However, surfaces of $1 \%$ and $15 \%$ alkali-treated jute fiber were not smooth. Therefore, tensile strength of green composite under thermal fatigue can be improved by surface roughness of $1 \%$ and $15 \%$ alkali-treated jute fiber up to $10^{2}$ cycles.
\end{abstract}

Keywords: green composite, natural fiber, polylactic acid, surface treatment, tensile property, thermal fatigue.

\section{INTRODUCTION}

Natural fiber reinforced biodegradable polymer (green composite) exhibits good mechanical performance because of the high specific modulus of natural fiber. Recently, a honeycomb structure using green composites are demanded for next-generation electric vehicles [1]. Therefore, mechanical properties of the green composites [2]-[11] have been assessed for use in such vehicles.

Many electric vehicle components undergo thermal fatigue. For this reason, mechanical properties of green composite should be investigated under thermal fatigue.

Katogi et al. [12] reported residual tensile properties of green composites under thermal fatigue. At temperatures of $35-45^{\circ} \mathrm{C}$ and $35-55^{\circ} \mathrm{C}$, the tensile strength of green composites at $10^{3}$ cycles became lower than that of a green composite at 0 cycles.

Generally, interfacial adhesion between natural fibers and biodegradable polymers is not good. For this reason, many reports have described mechanical properties of surface-treated natural fiber and composites [13]-[15].

Katogi et al. [16] elucidated some effects of alkali treatment (1-5\% concentration) on tensile properties of jute fiber under environmental temperatures. The tensile strength of $1 \%$ alkali-treated jute fiber showed a maximum value under $100^{\circ} \mathrm{C}$. Haraguchi et al. [17] reported impact properties of ramie plied yarn reinforced green composite after alkali 
treatment. The impact properties of ramie plied yarn reinforced green composite were improved by $15 \%$ alkali treatment. In this way, tensile properties of green composites under thermal fatigue can be improved by $1 \%$ and $15 \%$ alkali treatment.

This study examined thermal fatigue effects on tensile properties of green composite using alkali-treated jute fiber. In addition, tensile properties of polylactic acid (PLA) were investigated after thermal fatigue.

\section{SPECIMENS AND SURFACE TREATMENT}

\subsection{Materials}

The matrix was a PLA sheet (Ecodear 250-1B01CA; Toray Co. Ltd.). Reinforcement was of plain woven cloth of jute fibers.

\subsection{Alkali treatment}

Alkali treatment of the plain woven jute fiber cloth was conducted. The alkali treatment concentrations were $1 \%$ and $15 \%$. The treatment time was $2 \mathrm{hr}$. The environmental temperature was room temperature. Fig. 1 portrays plain woven jute fiber cloth before and after alkali treatment. Furthermore, Fig. 2 shows jute fiber surfaces before and after alkali treatment. As shown in Figs 1 and 2, the color of plain woven cloth of jute fiber changed from yellow to brown when $1 \%$ and $15 \%$ alkali treatments were applied. And, surface of jute fiber became gradually rough up to $15 \%$ concentration of alkali treatment. The surface of alkali-treated jute fiber will be discussed in the following Section 4.2.

\subsection{Molding method and specimens}

Molding of the green composite was done using vacuum compression molding at $1.7 \mathrm{MPa}$ for $10 \mathrm{~min}$. The molding temperature was $190^{\circ} \mathrm{C}$. Thereafter, the mold was cooled to room temperature. The fiber volume fraction of the green composite was $45 \%$. The green composite specimen was $150 \mathrm{~mm}$ long, $10 \mathrm{~mm}$ wide, and $2.0 \mathrm{~mm}$ thick.

The PLA plate molding method was vacuum compression molding at $0.4 \mathrm{MPa}$ for 10 min. The molding temperature was $190^{\circ} \mathrm{C}$. Thereafter, the mold was cooled to room temperature. The PLA specimen was dumbbell-shaped. The PLA specimen size was $85 \mathrm{~mm}$ long and $4.0 \mathrm{~mm}$ thick.

\section{TESTING METHODS}

\subsection{Thermal fatigue testing}

Thermal fatigue tests were conducted of non-treated and alkali-treated green composite and PLA. The temperatures were $35-80^{\circ} \mathrm{C}$. The heating time was $90 \mathrm{~s}$; the cooling time was 90

$\mathrm{s}$. The maximum number of cycle was $10^{3}$ cycles. The number of specimens was five.

\subsection{Quasi-static tensile testing}

Before and after thermal fatigue testing, quasi-static tensile tests of non-treated and alkali green composites were conducted based on Japanese Industrial Standard (JIS) K 7054. In addition, quasi-static tensile test of PLA was conducted based on JIS K 7162. The gauge 

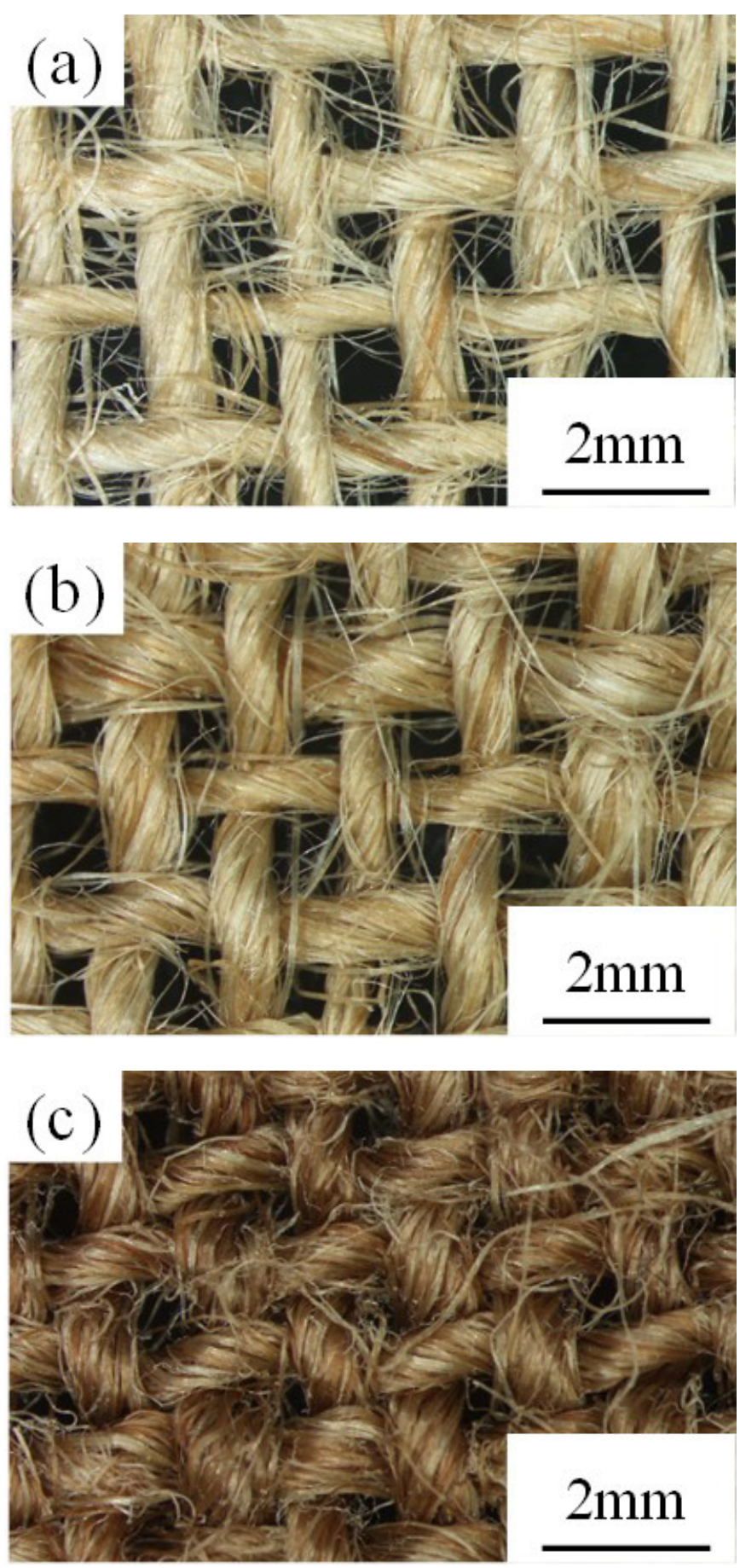

Figure 1: Plain woven jute fiber cloth before and after alkali treatment. (a) Non-treated; (b) $1 \%$ alkali-treated; and (c) $15 \%$ alkali-treated. 
62 High Performance and Optimum Design of Structures and Materials III
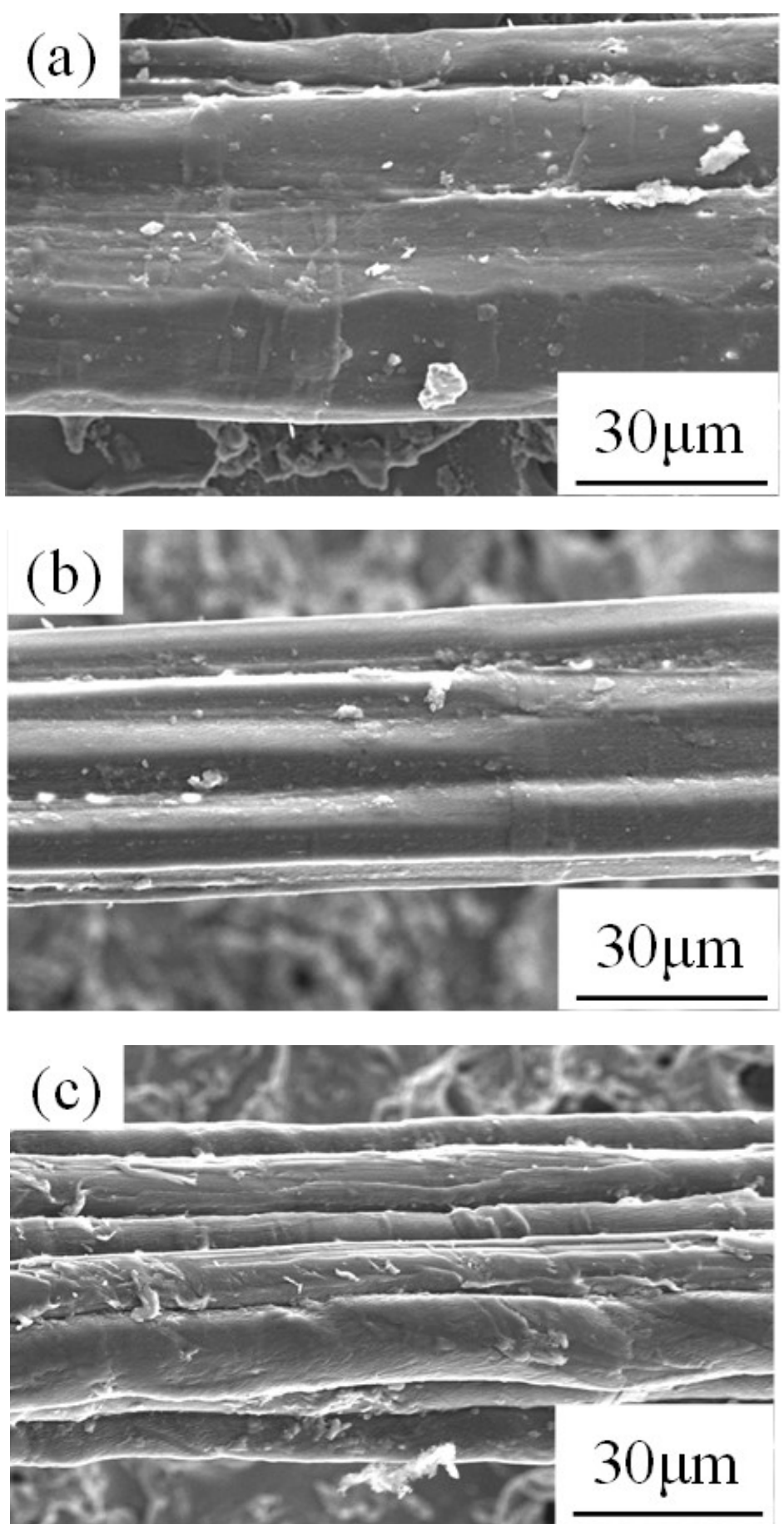

Figure 2: Jute fiber surfaces before and after alkali treatment. (a) Non-treated; (b) $1 \%$ alkali-treated; and (c) 15\% alkali-treated. 
length was $25 \mathrm{~mm}$. The environmental temperature was room temperature. The crosshead speed was $1.0 \mathrm{~mm} / \mathrm{min}$. The number of specimens was five.

After quasi-static tensile testing, fracture morphologies of non-treated and alkali-treated green composites were observed using optical microscopy (SZY7; Olympus Corp.).

\section{RESULTS AND DISCUSSION}

\subsection{Quasi-static tensile property after thermal fatigue testing}

Fig. 3 shows tensile properties of PLAs before and after thermal fatigue. The tensile strength and Young's modulus of PLA at 0 cycles were, respectively, $59 \mathrm{MPa}$ and $3.3 \mathrm{GPa}$. Scattering of the tensile strength and Young's modulus of PLA was low before and after thermal fatigue. The tensile strength and Young's modulus of PLA remained almost unchanged with an increase of number of cycles until $10^{3}$ cycles. From that result, one can infer that tensile properties of PLA were unaffected by thermal fatigue.

Fig. 4 depicts thermal fatigue effects on tensile properties of non-treated and alkalitreated green composites. Tensile strengths of non-treated and $1 \%$ and $15 \%$ alkali-treated green composites at 0 cycles were, respectively, $73 \mathrm{MPa}, 83 \mathrm{MPa}$, and $48 \mathrm{MPa}$. Furthermore, the Young's modulus of non-treated and 1\% and $15 \%$ alkali-treated green composites at 0 cycles were, respectively, $8 \mathrm{GPa}, 9 \mathrm{GPa}$, and $6 \mathrm{GPa}$. Scattering of tensile strength and Young's modulus of non-treated and $1 \%$ and $15 \%$ alkali-treated green composites were low before and after thermal fatigue, except for scattering of tensile strength and Young's modulus of $1 \%$ alkali-treated green composite at $10^{2}$ cycles. The tensile strength and Young's modulus of 1\% alkali-treated green composite showed the maximum value under all numbers of cycles. Moreover, the tensile strength and Young's modulus of $15 \%$ alkali-treated green composite showed minimum values at all numbers of cycles. When $1 \%$ alkali treatment was applied, the tensile properties of the jute fiber were increased by an increase in the rate of cellulose in constituent materials of jute fiber [16]. When $15 \%$ alkali treatment was applied, the cellulose I in jute fiber constituent materials changed to cellulose II [18]. The green composite tensile properties were affected mainly by the rate and modification of cellulose in constituent materials of alkali-treated jute fiber.

The tensile strength of non-treated green composite decreased monotonously with the number of cycles up to $10^{3}$ cycles. Nevertheless, the Young's modulus of the non-treated green composite remained unchanged up to $10^{2}$ cycles. Tensile properties of $1 \%$ and $15 \%$ alkali-treated green composites remained almost unchanged up to $10^{2}$ cycles. Tensile strengths of $1 \%$ and $15 \%$ alkali-treated green composites at $10^{3}$ cycles were lower by $23 \%$ and $28 \%$, respectively, than those of $1 \%$ and $15 \%$ alkali-treated green composites at $10^{2}$ cycles. Young's moduli of non-treated, $1 \%$, and $15 \%$ alkali-treated green composites at $10^{3}$ cycles were lower, respectively, by $31 \%, 30 \%$, and $27 \%$ than those of non-treated, $1 \%$ and $15 \%$ alkali-treated green composites at $10^{2}$ cycles.

Results show that $1 \%$ and $15 \%$ alkali treatments can improve the fiber-resin interfacial adhesion. In this way, tensile properties of $1 \%$ and $15 \%$ alkali-treated green composites under thermal fatigue were unaffected because of the prevention of debonding at the interface between the fiber and resin up to $10^{2}$ cycles. Even when $1 \%$ and $15 \%$ alkali treatments were conducted, tensile properties of green composite decreased because of debonding at the fiber-resin interface during $10^{2}$ cycles. 

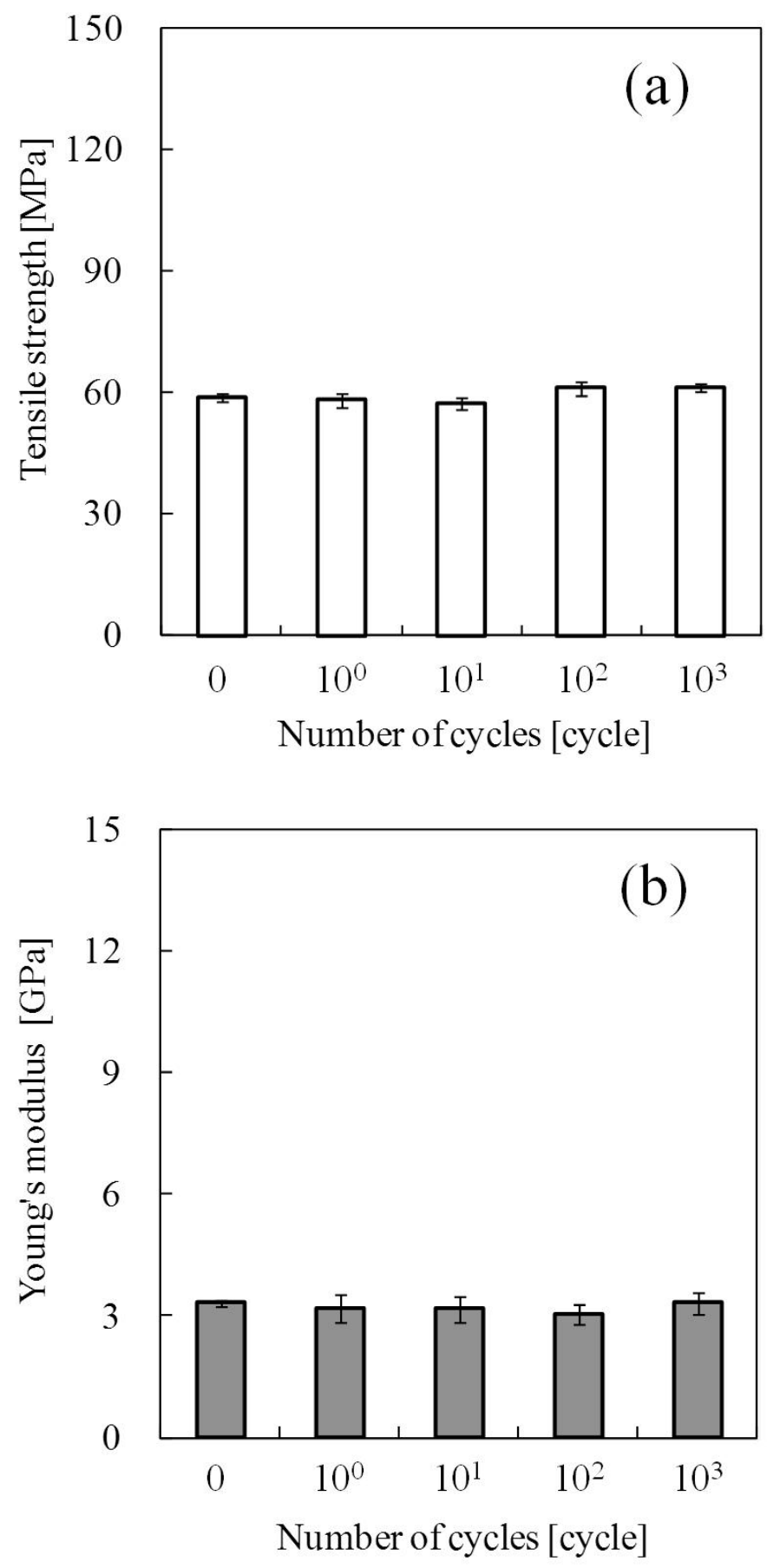

Figure 3: Tensile properties of PLAs before and after thermal fatigue. (a) Tensile strength; and (b) Young's modulus. 
High Performance and Optimum Design of Structures and Materials III 65
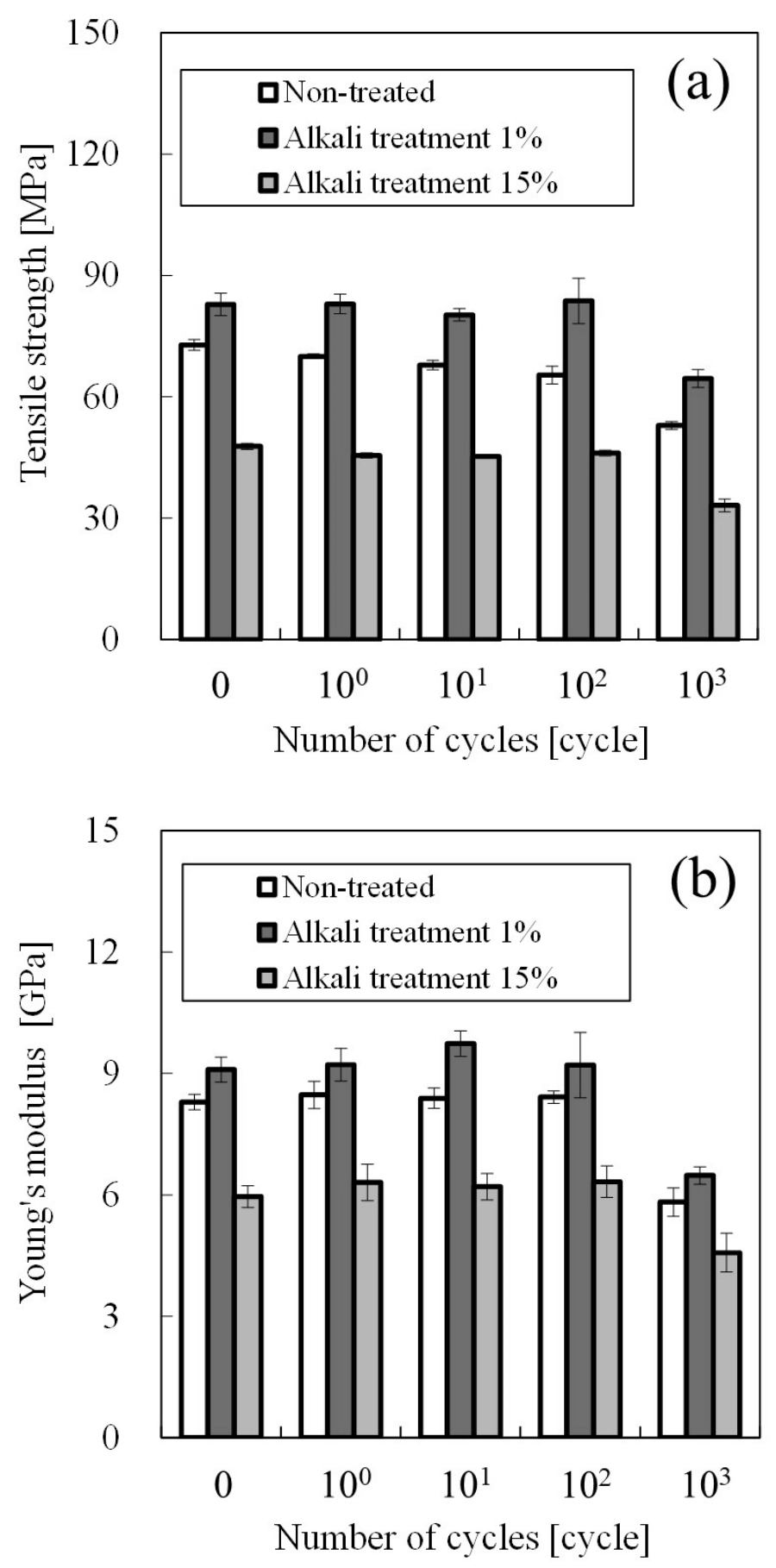

Figure 4: Effects of thermal fatigue on tensile properties of non-treated and alkali-treated green composites. (a) Tensile strength; and (b) Young's modulus. 


\subsection{Fracture morphology of non-treated and alkali-treated green composites}

Figs 5 and 6 respectively show the fracture morphologies of non-treated and alkali-treated green composites at 0 and $10^{3}$ cycles. Fracture morphologies of non-treated and $1 \%$ and $15 \%$ alkali-treated green composites at 0 cycles were smooth. However, considerable yarn pull out was found in the fracture morphology of non-alkali-treated green composite at $10^{3}$ cycles. Fracture morphologies of $1 \%$ and $15 \%$ alkali-treated green composites at $10^{3}$ cycles were smooth. As shown in Fig. 2, the surface of non-treated jute fiber was smooth. However, surfaces of $1 \%$ and $15 \%$ alkali-treated jute fiber were not smooth. Moreover, surfaces of $1 \%$ and $15 \%$ alkali-treated jute fibers were very rough compared to those of non-treated jute fiber. Elementary fibers were found on the $15 \%$ alkali-treated jute fiber surface. When the jute fiber was immersed in alkali solution, constituent materials on the jute fiber surface probably dissolved with increased alkali treatment concentration. Effect of concentration of alkali treatment on surface roughness of jute fiber will need to examine for clarification of mechanism in the future.

Results show that fiber-resin interfacial adhesion was probably improved by surface roughness of $1 \%$ and $15 \%$ alkali-treated jute fibers up to $10^{2}$ cycles. However, debonding probably occurred at the fiber-resin interface because of decreased interfacial adhesion by attributable to the different thermal expansions of non-treated and alkali-treated jute fibers and PLA over $10^{2}$ cycles. In addition, the fracture origin of $1 \%$ and $15 \%$ alkali-treated green composites might be initiated by debonding at the fiber-resin interface because of the surface roughness of $1 \%$ and $15 \%$ alkali-treated jute fibers. Results show that tensile strength of the green composite under thermal fatigue can be improved by surface roughness of $1 \%$ and $15 \%$ alkali-treated jute fibers up to $10^{2}$ cycles.

\section{CONCLUSIONS}

This study investigated thermal fatigue effects on tensile property of alkali-treated green composites. Results suggest the following conclusions.

Tensile strength and Young's modulus of 1\% alkali-treated green composite showed maximum values under all numbers of cycles. The tensile strength and Young's modulus of $15 \%$ alkali-treated green composite showed minimum values under all numbers of cycles. These results suggest that tensile properties of green composites were mainly affected by rates and modifications of cellulose in constituent materials of alkali-treated jute fiber.

The tensile strength of non-treated green composite decreased monotonously with increase in the number of cycles up to $10^{3}$ cycles. However, the Young's modulus of nontreated green composite did not change until $10^{2}$ cycles. Tensile properties of $1 \%$ and $15 \%$ alkali-treated-treated green composites remained almost unchanged until $10^{2}$ cycles. By contrast, tensile strengths of $1 \%$ and $15 \%$ alkali-treated green composites at $10^{3}$ cycles were much lower than those of $1 \%$ and $15 \%$ alkali-treated green composites at $10^{2}$ cycles. In addition, Young's moduli of non-treated and $1 \%$ and $15 \%$ alkali-treated green composites at $10^{3}$ cycles were lower than those of non-treated and $1 \%$ and $15 \%$ alkali-treated green composites at $10^{2}$ cycles. Nevertheless, the tensile strength and Young's modulus of PLA remained almost unchanged under thermal fatigue. Fracture morphology observations revealed large yarn pull out in the non-alkali-treated green composite at $10^{3}$ cycles. Fracture morphologies of $1 \%$ and $15 \%$ alkali-treated green composites at $10^{3}$ cycles were smooth. Surface observations revealed smooth non-treated jute fibers, but non-smooth surfaces of $1 \%$ and $15 \%$ alkali-treated jute fibers. Results show that the tensile strength of green a composite under thermal fatigue can be improved by surface roughness of $1 \%$ and $15 \%$ alkali-treated jute fibers up to $10^{2}$ cycles. 
High Performance and Optimum Design of Structures and Materials III 67
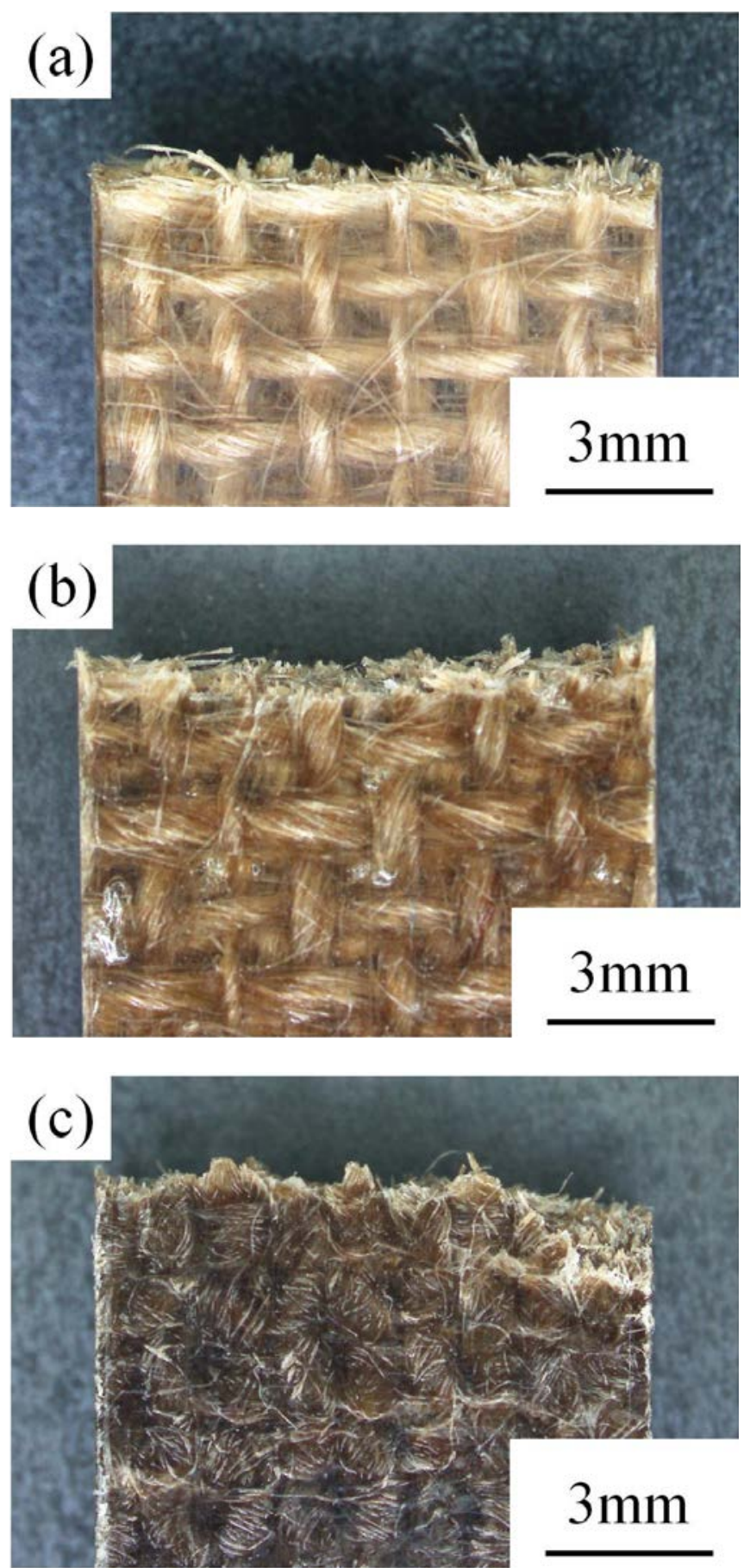

Figure 5: Fracture morphologies of non-treated and alkali-treated green composites before thermal fatigue ( 0 cycles). (a) Non-treated; (b) Alkali treatment $1 \%$; and (c) Alkali treatment $15 \%$. 

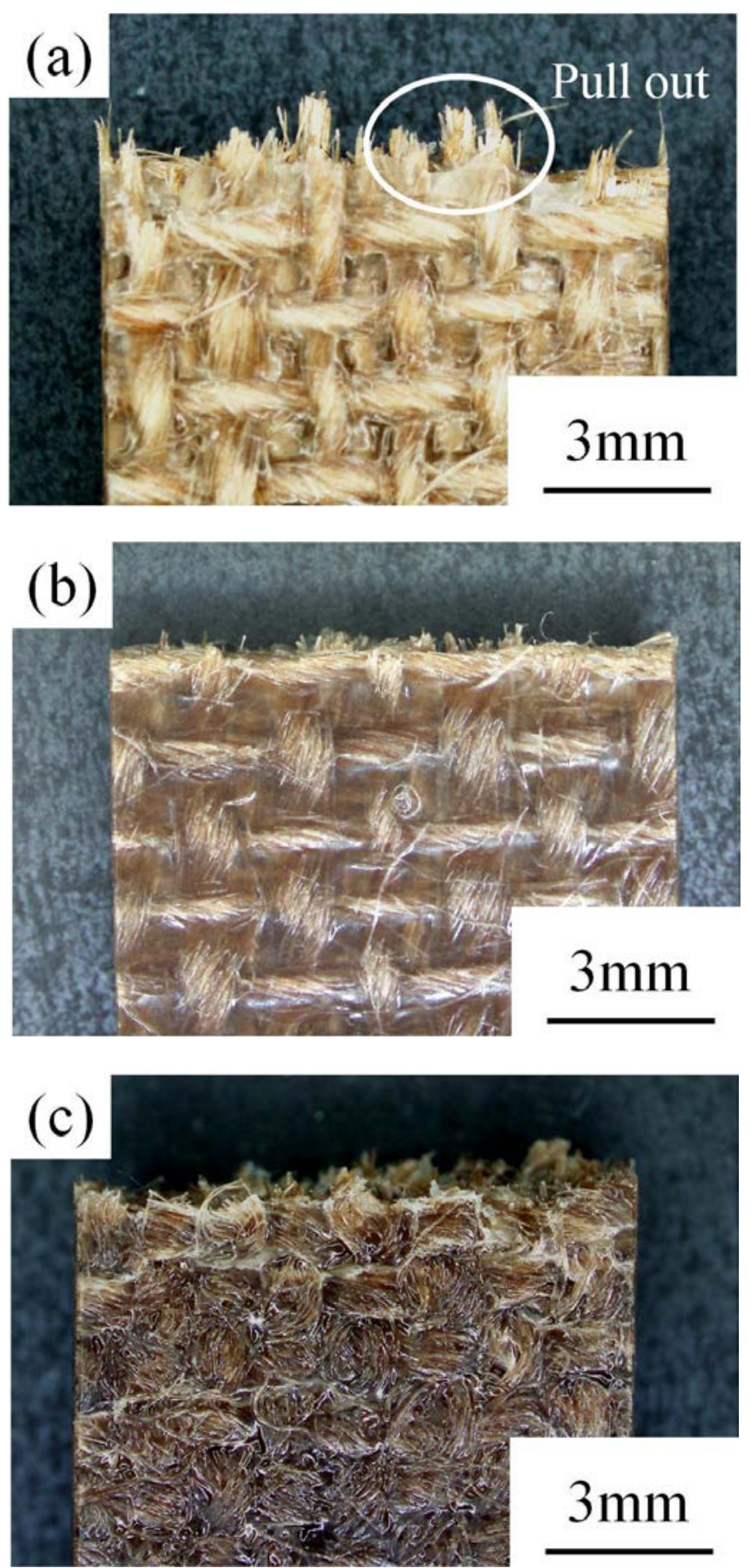

Figure 6: Fracture morphologies of non-treated and alkali-treated green composites after thermal fatigue ( $10^{3}$ cycles). (a) Non-treated; (b) Alkali treatment 1\%; and (c) Alkali treatment $15 \%$. 


\section{ACKNOWLEDGEMENT}

This study was partially supported by educational research funds from the KYURYOKAI, Kanagawa University, Japan (2017).

\section{REFERENCES}

[1] JEC Group, http://www.jeccomposites.com/knowledge/international-compositesnews/lina-bio-composite-based-car-pla-honeycomb-sandwich-design.

[2] Tanaka, K., Katsura, T., Shinohara, M., Morita, Y., Katayama, T. \& Uno, K., Heatresistant and mechanical property of jute continuous fiber reinforced PLA. Journal of the Society of Material Science, Japan, 59, pp. 546-552, 2010 (in Japanese).

[3] Katogi, H., Shimamura, Y., Tohgo, K. \& Fujii, T., Fatigue behavior of unidirectional jute spun yarn reinforced PLA. Advanced Composite Materials, 21, pp. 1-10, 2012.

[4] Kobayashi, S. \& Takeda, K., Transverse properties of hemp/PLA composite fabricated with micro-braiding technique. Advanced Composite Materials, 24, pp. 509-518, 2015.

[5] Takagi, H., Nakagaito, A.N., Nishimura, K. \& Matsui, T., Mechanical characterisation of nanocellulose composites after structural modification. WIT Transactions on the Built Environment, vol. 166, WIT Press: Southampton and Boston, pp. 335-341, 2016.

[6] Tanaka, K., Shiga, T. \& Katayama, T., Fabrication of hydroxyapatite/PLA composite nanofiber by electrospinning. WIT Transactions on the Built Environment, vol. 166, WIT Press: Southampton and Boston, pp. 371-379, 2016.

[7] Sukmawan, R., Takagi, H. \& Nakagaito, A.N., Strength evaluation of cross-ply green composite laminates reinforced by bamboo fiber. Composites Part B: Engineering, 84, pp. 9-16, 2016.

[8] Wei, L. \& Mcdonald, A.G., A review on grafting of biofibers for biocomposites. Materials, 9, pp. 303-326, 2016.

[9] Morreale, M., Mistretta, M.C. \& Fiore, V., Creep behavior of poly(lactic acid) based biocomposites. Materials, 10, pp. 395-407, 2017.

[10] Ullah, S.A.M.M., Shahinur, S. \& Haniu, H., On the mechanical properties and uncertainties of jute yarn. Materials, 10, pp. 450-464, 2017.

[11] Katogi, H. \& Takemura, K., Creep rupture of water-absorbed green composite. WIT Transactions on Engineering Sciences, vol. 116, WIT Press: Southampton and Boston, pp. 281-288, 2017.

[12] Katogi, H., Takemura, K. \& Akiyama, M., Residual tensile property of pain woven jute fiber/poly(lactic acid) green composites during thermal cycling. Materials, 9, pp. 573-583, 2016.

[13] Ray, D., Das, M. \& Mitra. D., Influence of alkali treatment on creep properties and crystallinity of jute fiber. Bioresources, 4, pp. 730-739, 2009.

[14] Yu, T., Ren, J., Li, S., Yuan, H. \& Li, Y., Effect of fiber surface-treatments on the properties of poly(lactic acid)/ramie composites. Composites Part A: Applied Science and Manufacturing, 41, pp. 499-505, 2010.

[15] Gibeop, N., Lee, D.S., Prasad, C.V., Toru, F., Kim, B.S. \& Song, I.J., Effect of plasma treatment on mechanical properties of jute fiber/poly(lactic acid) biodegradable composites. Advanced Composite Materials, 22, pp. 389-399, 2013.

[16] Katogi, H., Takemura, K. \& Suzuki, R., Tensile properties of surface treated jute fiber under high environmental (ambient) temperatures. WIT Transactions on Engineering Sciences, vol. 90, WIT Press: Southampton and Boston, pp. 37-45, 2015. 
70 High Performance and Optimum Design of Structures and Materials III

[17] Haraguchi, K., Suizu, N., Uno, T., Goda, K., Noda, J. \& Ohgi, J., Effect of alkali treatment on the tensile and impact properties of ramie plied yarn-reinforced green composites. Journal of the Society of Material Science, Japan, 58, pp. 374-381, 2009 (in Japanese).

[18] Katogi, H., Takemura, K. \& Sebori, R., Fatigue property of natural fiber after alkali treatment. WIT Transactions on the Built Environment, vol. 166, WIT Press: Southampton and Boston, pp. 343-350, 2016. 